\title{
PROIBICIONISMO E ATENÇÃO EM SAÚDE A USUÁRIOS DE DROGAS: TENSÕES E DESAFIOS ÀS POLIÍTICAS PÚBLICAS
}

\author{
PROHIBICIONISMO $\Upsilon$ LA ATENCIÓN DE SALUD A LOS USUARIOS DE \\ DROGAS: TENSIONES Y DESAFÍOS PARA LAS POLÍTICAS PÚBLICAS \\ PROHIBITION AND HEALTH CARE FOR DRUG USERS: TENSIONS \\ AND CHALLENGES TO PUBLIC POLICIES
}

\author{
Fábio José Orsini Lopes ${ }^{1}$
}

${ }^{1}$ Universidade Estadual de Maringá, Maringá/PR, Brasil

RESUMO: O presente trabalho tem como intuito promover discussão acerca da temática de uso e abuso de álcool e outras drogas na sociedade atual. Objetiva refletir sobre os modelos e práticas de atenção a usuários de drogas em meio às políticas públicas atualmente em voga. Parte do reconhecimento sobre a presença do uso de substâncias psicoativas em diferentes contextos e momentos históricos, para, então, discorrer sobre o uso e abuso de drogas. Destaca, ainda, o modelo de atenção psicossocial para usuários de drogas em sua relação com a cultura proibicionista e ações de repressão e intolerância às drogas. Por fim, o artigo conclui que as atuais políticas públicas de atenção aos usuários, incluída a lógica da redução de danos, se encontram em rota de colisão e tensionamento com o ainda predominante proibicionismo e com a velada e desassistida cultura de consumo de drogas.

PALAVRAS-CHAVE: Proibicionismo; Políticas sobre Drogas; Atenção aos usuários.

RESUMEN: El presente trabajo tiene como objetivo promover la discusión sobre uso y abuso de alcohol y otras drogas en nuestra sociedad hoy en día. Así, pretende reflexionar sobre los modelos y prácticas de atención a usuarios de drogas, en medio de las políticas públicas actualmente en boga. Por lo tanto, parte del reconocimiento de la presencia de sustancias psicoactivas utilizar en diferentes contextos y momentos históricos y luego discutir el uso y abuso de drogas en nuestra sociedad hoy en día. Aún así, pone de relieve el modelo de atención psicosocial para los usuarios de drogas, en su relación con la cultura prohibicionista y las acciones de represión e intolerancia a los medicamentos. Por último, el artículo concluye que la actual política pública de atención a usuarios, incluyendo la lógica de reducción de daños, presentase en un curso de colisión y tensión con la prohibición imperante y aún con la cultura con velo y sin ayuda del consumo de drogas.

PALABRAS-CLAVE: Prohibicionismo; Políticas acerca de las drogas; Atención a los usuarios.

ABSTRACT: The present work aims to promote discussion about the use and abuse of alcohol and other drugs in our current society. It aims to reflect on the models and practices of attention to drug users, in the midst of public policies currently in vogue. The work starts by recognizing the presence of the use of psychoactive substances in different contexts and historical moments, to then discuss the use and abuse of drugs in our current society. Also, it emphasizes the model of psychosocial attention for drug users, in its relation with the prohibitionist culture and actions of drug repression and intolerance. Finally, the article concludes that the current public policies of attention to users, including the harm reduction logic, are on a collision and tensioning route with the still predominant prohibition and with the veiled and unassisted drug consumer culture.

KEYWORDS: Prohibition; Policy on Drugs; Attention to Users. 


\section{Introdução}

Em meio às forças e saberes renovados que gravitam atualmente sobre a "questão das drogas", talvez seja possível afirmar que há um ponto de partida comum: o reconhecimento de que diferentes tipos de uso de drogas estiveram inexoravelmente presentes em todos os tipos de formação social na história da humanidade. Autores de calibres reconhecidos, entre os quais Escohotado (2005), Rose (1999), MacRae (1994), Karam (2009), Fuente (1992), Rodrigues (2006), entre outros, sustentam este entendimento da contiguidade da relação entre a humanidade e as drogas. Tal reconhecimento se encontra, portanto, na base das considerações contemporâneas que apontam para a ubiquidade das drogas em sua relação com a humanidade.

Nesta perspectiva, consideramos o uso e o abuso de drogas como expressões e resultado das configurações socioculturais presentes em nossa sociedade. Tais configurações apontam para um sem-número de condicionantes estruturais que, no tocante às drogas, englobam tantos aspectos quanto possíveis, pois sofrem influências diretas de fatores econômicos, jurídicos, sociais, culturais e os relativos à conformação intersubjetiva contemporânea. Uma temática tão diversamente atravessada, que determina imediatamente o rechaço de medidas simplistas, em especial as que se propõem resolutivas e terminantes, muitas delas calcadas em crenças sobre o endurecimento de leis coercitivas ou na cessação da oferta de drogas, por meio de ações beligerantes.

Dadas essas características multidiversificadas e enraizadas em diferentes perspectivas históricas, sociais, culturais e econômicas, propostas de análise e interpretação dos fenômenos que envolvem o uso e o abuso de substâncias psicoativas por uma dada sociedade exigem certa extensão metodológica condizente com a multiplicidade aventada do objeto-drogas. Isto porque a temática do uso e abuso de drogas nas sociedades contemporâneas e os modelos de atenção oferecidos como resposta se configuram como objetos essencialmente fugidios, por uma dupla razão: de um lado, o proibicionismo, como se verá, determinou consequências e desdobramentos variados para o comércio internacional, os sistemas judiciários, as relações diplomáticas, entre outros determinantes. Mas, em especial, se poderia dizer que o proibicionismo foi responsável também pela implantação de uma espécie de véu ocultador, um velamento de condições de acesso ao que se poderia chamar de "verdade científica" sobre as drogas, determinando também o conjunto de produção de conhecimento sobre elas. Durante todo o século XX, a ciência e a fabricação do consenso sobre as drogas mantiveram seu foco na nocividade a priori das substâncias e, portanto, outras perspectivas foram simplesmente silenciadas.

A segunda razão da dificuldade inicial que a natureza do objeto desta pesquisa oferece é que, no tocante à análise dos modos de atenção e paradigma alternativos ao usuário, o fato de estarmos vivendo exatamente no momento em que este processo tem início, certamente oferece limitações às intenções conclusivas. O clássico raciocínio dedutivo que apontaria incólume e seguramente para uma "solução" ao "problema-drogas" está aqui, de antemão, descartado. Neste sentido, a proposta deste artigo se arvora, inicialmente, na noção de "problematização", emprestada de Thompson (2012), para quem o conceito se refere à análise acerca das condições (sociais, culturais, políticas, econômicas) que possibilitam o surgimento e a permanência de determinados discursos e práticas na sociedade. O uso de drogas é, profundamente, uma temática construída sob certos determinantes, e os discursos e verdades produzidos a seu respeito acompanharam escusas configurações a 
serem decifradas. O método investigativo proposto por Thompson (2012), conhecido como "hermenêutica da profundidade" coloca em destaque o fato de entender a suposta essência das coisas como algo que repouse no plano do eminentemente simbólico, social e historicamente construído.

Entre essas diversas condições estruturais, pode-se partir do entendimento que reconhece a formação de um olhar sobre as práticas de uso e abuso de drogas em sua relação com a "economia" da circulação das drogas. Seculares, o comércio e abastecimento de drogas marcaram substancialmente a expansão e evolução dos mercados e das relações de troca internacionais, tendo sido fortemente intensificado e geopoliticamente ressignificado nos últimos dois séculos. Na sociedade contemporânea, as drogas representam um tipo de mercadoria fungível de total e completa identificação com a atual face do modo capitalista de produção, cuja expressão maior se volta para formação de mercado consumidor. Este momento fez do ato de consumir não somente o elemento que configura a razão de ser deste modo de produção, mas, o que nos é diretamente pertinente, também afeta a produção de subjetividade e impacta o lugar que o consumo ocupa na conformação social intersubjetiva. Portanto, este é um primeiro elemento sobre o qual devemos nos ater: a atual economia capitalista de consumo, em um mercado dito flexível, encontra na produção e no consumo de drogas condições ideais de expansão, adaptação e sobrevivência. Capitalismo e drogas representam categorias de análise diretamente intercomunicáveis e construídas em relação de interdependência.

Em segundo lugar, entendemos que as análises sobre uso e abuso de drogas devam, também, considerar o lugar que elas têm ocupado na "economia psíquica" das relações intersubjetivas. Entre algumas premissas sobre a relação drogas-subjetividade, talvez seja possível destacar o entendimento de que os fenômenos de abuso de drogas são identificados como sintomas de um mal-estar social e subjetivo presentes na cultura contemporânea; e a partir da modernidade, principalmente. Esta cultura é testemunha de uma perda na condição de certa 'inteligência intuitiva' para o uso de drogas, verificada em diferentes momentos anteriores na relação da humanidade com as drogas. Os fenômenos de adição missivas, modernamente nominados como de "dependência química", estão atrelados a condições de vida intersubjetivas relativamente recentes. O raciocínio não é novo nem tampouco nosso, mas deve-se reconhecer o entendimento de que o funcionamento psíquico e a conformação subjetiva do (frágil) vir a ser humano, na atual conjuntura social e cultural, estão submetidos a um nível de produção de ansiedade e sofrimento psíquicos até então desconhecidos. Uma breve análise sobre este cenário nos enseja algumas considerações.

\section{Do mal-estar contemporâneo ao abuso de drogas}

Primeiramente, há que se destacar, no que diz respeito à relação com a atual fase do modo de produção capitalista, guiada pela exacerbação do consumo, a condição em que os sentimentos de pertença e inclusão sociais passam a ser, também, mediados e definidos pelas condições e práticas de consumo. Um cenário em que processos de subjetivação são validados e valorizados, nos diferentes estratos sociais, pelo ato de consumir. Dadas as desigualdades intrínsecas ao funcionamento do modo de produção capitalista, contingente social largamente majoritário permanece e permanecerá ausente e excluído deste caminho integrativo. Exclusão, desintegração e desamparo soam como uma fórmula sequencial dos 
resultados.

Também outras categorias de análise se apresentam, em especial as relacionadas à cultura viva e à produção de conhecimento. Nas sociedades ditas pós-modernas, entre seus elementos definidores encontra-se o colapso da própria condição de produção do saber e rachaduras no lugar da razão como ordenadora da vida social. A perda de força das narrativas oficiais e o enfraquecimento da autoridade e da tradição como balizas também compõem este cenário anunciador de certo abandono e desalento. Soma-se a este quadro o cenário de crise em que se inserem as propostas formativas oficiais e tem-se boa medida de quão ausentes de parâmetros e sustentação cultural se encontram os processos de conformação intersubjetivos. O resultado, novamente, não poderia ser outro senão o mesmo desalento e a mesma desassistência face aos quais o sujeito contemporâneo se encontra.

No âmbito da produção da vida material, também o cenário pode ser considerado desestabilizador e produtor de tensionamento psíquico e intersubjetivo. De um lado, as crescentes e reiteradamente negativas previsões acerca da insustentabilidade da lógica e dos efeitos do modo de produção no qual estamos inseridos. Discursos, entendimentos e mesmo exemplos dessa inviabilidade se mostram alhures. Não raro, previsões sobre irreversibilidade na formação de um cenário ambiental catastrófico figuram como certas, a permanecer as condições de produção e consumo. Por outro lado, tem-se um contexto de desmonte, transformação e precarização do mundo do trabalho, o que enseja um sem número de distintos e intensos questionamentos sobre alguns elementos fundamentais na construção de processos de formação subjetiva e sociais. De forma forçosamente resumida, poder-se-ia dizer: trabalho em xeque, sujeito idem.

Por último, mas nada menos importante, finalizando este esboço constitutivo de um pano de fundo social esquemático, sobre o qual assentam alguns aspectos que entendemos relativos ao cenário de uso e abuso de drogas, poderia ser arrolada a característica de liquidez das relações intersubjetivas e afetivas, somada ao esvaziamento dos espaços públicos e da vivência coletiva. A exacerbação do individualismo e a transitoriedade fugidia nas relações de afeto são marcadamente caracterizadoras do atual estado de transações subjetivas e inter-relacionais, denunciando o abandono afetivo no qual o sujeito contemporâneo está inserido.

\section{O gerenciamento das drogas e de seus usuários}

O resultado da confluência destes fatores interdeterminantes se mostra, hoje, uma questão desafiadora em termos de gerenciamento de políticas sobre drogas e da oferta de cuidados a usuários. O momento configurado expõe um cenário em que é verificada, entre outras tensões, a convivência entre o aceno de uma política integral de atenção ao usuário, por um lado, e o recrudescimento de forças proibitivas e punitivas à circulação de drogas, por outro. No mesmo dispositivo legal regulador da questão, ambas as premissas figuram como norteadoras das "soluções" propostas, evidenciando a fissura contemporânea básica no seio da proteção aos direitos de liberdade e segurança. O entendimento que ensaia emergir dos dispositivos regulatórios não parece dar conta dessa tensão entre a defesa dos direitos subjetivos, entre os quais encontramos as raízes da implicação subjetiva da atenção psicossocial, e as tecnologias de intervenção e controle dos corpos e dessa mesma subjetividade "assujeitada". 
As soluções atualmente em voga e ensaiadas como resposta ao "problema-drogas", representadas pela aplicação das políticas nacional sobre drogas e de atenção integral ao usuário, acabam por sussurrar não ditos e tergiversar acerca de outras possibilidades (Lei Federal n. 11343/2006; Ministério da Saúde, 2003a, 2003b, 2004). Um campo de arranjos sociais, culturais e científicos que permeiam os desentendimentos conformadores da razão e obliteram a produção de discursos opostos ou minimamente alternativos ao paradigma reinante. Para o pesquisador Sérgio Alarcon (2008), este campo pode ser compreendido como sendo de convivência entre os ciclos de interdição e tolerância às drogas. Pelo entendimento da interdição, as drogas representariam um mal em si, sobre o qual caberia ao gerenciamento biopolítico ${ }^{1}$ do Estado se antecipar e buscar o cerceamento das liberdades individuais em benefício dos discursos de segurança e de proteção aos sujeitos. Pela perspectiva da tolerância, o uso de drogas representaria expressão legítima da cultura e da vivência humana, e o usufruto de substâncias psicoativas figuraria entre os princípios da defesa de direitos inalienáveis e próprios à condição de construção da subjetividade; restando ao controle biopolítico a minimização dos danos inerentes.

A perspectiva-interdição é de caráter preventivista e de redução de riscos, enquanto a perspectiva-tolerância se utiliza em geral de discursos que privilegiam a liberdade individual através da promoção da qualidade de vida pessoal, em um saber-viver que admite apenas um mínimo de intervenção pública relacionada, no máximo, a práticas ${ }^{2}$ de Redução de Danos. Dessa maneira, a interdição realçaria aspectos de obediência, tornando ao mesmo tempo a desobediência inadmissível, enquanto a tolerância redimiria aspectos de desobediência, incorporando-a a um sistema mais flexível de dominação. Para a perspectiva-interdição, a tolerância demarca uma exterioridade ao poder soberano por demais perigosa, enquanto a perspectiva-tolerância relaciona a in terdição a uma perda de liberdade insuportável e incompatível com as razões de ser do poder como organizador do sistema social. (Alarcon, 2008, pp. 218-219)

As atuais propostas esboçadas pela gestão em saúde, na tentativa de convivência com o gerenciamento biopolítico representado pelas forças de repressão do Estado, têm criado um cenário multifacetado e cindido, no qual se constata um bom número de interpretações distintas. O mal-estar social contemporâneo causado pelo uso e abuso de drogas acaba por refletir na percepção inconteste da existência dessas variações na interpretação do sistema regulatório das drogas, marcado fortemente pelas condições socioeconômicas dos usuários e das características do tráfico. O tratamento jurídico, o encaminhamento penal e mesmo o julgamento social sobre casos emblemáticos oferecem à sociedade um mosaico de questionamentos e incompreensões, que auxiliam a fomentar nossa (quase completa) ignorância sobre as drogas. Se aprofundadas, as inquirições que apontam para os inúmeros matizes acerca da regulação e circulação das drogas deverão também incluir, entre outras questões, a lógica de sustentação de todo o sistema financeiro internacional, cujo papel de lavagem e regulamentação de fortunas em circulação já é plenamente conhecido.

Assim, temos a formação de um sistema regulatório do gerenciamento das drogas assemelhado a um enigma a ser decifrado. Um fractal de combinação entre repressão/ interdição e permissão/relativização que compõem o olhar e as ações de nossa sociedade sobre as drogas. Um sistema que encontra nesta polaridade condições de se auto e retroalimentar, pois cria dispositivos de realização tanto das condições de repressão quanto de 
tolerância. A presença de frestas de permissividade em meio à lógica proibitiva parece funcionar como reforçadores do próprio proibicionismo, pois auxiliam na definição seletiva das permissões toleradas pela sociedade. A interpretação do sistema jurídico-regulatório sobre as drogas, como é bem sabido e demonstrado, possui orientação arbitrária e socioeconomicamente definida, e muito pouco relativa às condições concretas de saúde. Esse sistema regulatório é amplamente seletivo em seu julgamento sobre nocividade e risco real à saúde, deixando transparecer, a rigor, um entendimento falacioso e hipócrita sobre as drogas. A mesma sociedade que se escandaliza e se choca com o consumo de drogas nas "cracolândias" é a que nada faz para reconhecer os impactos extremamente nocivos do maciço, alastrado e indiscriminado consumo de álcool. Também é a mesma sociedade que estigmatiza e moraliza o usuário de maconha e consome, em crescimento exponencial, medicamentos psicotrópicos de forma completamente descontrolada.

Na perspectiva de análise com a qual este artigo comunga, a afirmação de que o sistema regulatório e interpretativo sobre as drogas se constitui em um interjogo de interesses relacionados e, em aparência, contraditórios, encontra eco entre alguns pesquisadores. Tal entendimento sugere que as forças em colisão neste arcabouço interpretativo e normatizador sustentam, na prática, a própria sobrevivência e manutenção da mesma tensão que denunciam, pois que todo um conjunto de estratégias, proposições e dispositivos são forjados e criados na esteira deste campo tensionado. Assim, determinada parcela de usuários de drogas, portadores de discursos e de comportamentos identificados neste tensionamento interpretativo como reprováveis, podem servir à sociedade como párias sociais, balizadores e justificadores das ações de intervenção e exercício de poder, bem como das prescrições e orientações em saúde.

A existência do transgressor faz parte da economia “tensional” que une repressão/ transgressão/tolerância. Essa tensão se reproduz a si mesma na medida em que cria e recria a própria condição do ato transgressivo através daquilo que interdita ou tolera. Espera-se secretamente pelo transgressor, aquele que será o complexo exemplar pelo qual a natureza hedonista se fará contraditória, para reafirmar ao individualismo do homem contemporâneo que, se tudo é permitido, é intolerável abandonar a torrente múltipla dos prazeres por força de um desejo tão absoluto, como o daquele que quer apenas consumir drogas. Ao dispositivo das drogas, o importante não são aqueles que se colocam obedientes e dóceis à proibição, mas justamente aqueles que se deixam levar pelo absoluto prazer de um desejo tantas vezes incitado, e que por ele chegam ao ponto da inefável transgressão. A transgressão, cirurgicamente restrita ao hábito de determinadas drogas, opera positivando os fatores de segregação e hierarquização social, garantindo relações de dominação direta entre as instituições jurídico-policiais e o indivíduo tornado "perigoso". Além disso, produz também efeitos indiretos de hegemonia sobre o tipo de corpo e desejo considerados adequados socialmente. Esses "recortes" são feitos ao mesmo tempo pelas instâncias de medicalização do Estado, da sociedade civil ou do mercado - todos a contaminarem a "vontade de transgressão" não apenas com o vírus da má consciência, mas antes, e principalmente, com a vontade de liberdade. Por trás dos discursos moralistas não está a valorização do ascetismo, como em geral se pensa, mas, inversamente, a supremacia de uma individualidade capaz de exercitar o tipo de liberdade necessária à alma hedonista: se auto-estilizar, autogerenciar, ser responsável - 
em suma, capaz de um autocontrole para fins, por certo, muito pouco castos". (Alarcon, 2008, p. 215)

A convivência entre dispositivos de proibição e tolerância sugere um ciclo de aparente alternatividade, mas que, na verdade, tem promovido a continuidade do paradigma proibitivo e excludente. Aos usuários de drogas lícitas, nenhum conjunto de orientação minimamente pautado nos conhecimentos sobre a relação entre risco, dano e subjetividade parece ser anunciado; o consumo de álcool e de medicamentos psicotrópicos alcança números absolutos expressivos e nocividade relativa ainda mais agravada, dado o cenário de desorientação. Além disso, permanecemos fortemente mobilizados e estimulados por uma cultura de consumo desenfreado, que, além de nocivo, se mostra desnecessário e insustentável. Já aos usuários de drogas ilícitas resta permanecer em condições de marginalidade, exclusão e silenciamento de suas práticas e necessidades, como impossibilidades de pensar a atenção e promoção de saúde.

O controle do Estado sobre as práticas de uso de drogas se torna, então, difuso e, na aparência, abrandado. Os discursos sociais que apontam para a tolerância são, na prática, bulários de autocontrole e esboçam-se alguns sobre moderação ao consumo de drogas lícitas e permanece quase absoluta a desconsideração com o consumo das ilícitas. Em que pese o fato de alguns setores da sociedade emprestar voz a interpretações que apontam a falência dessa divisão jurídico-penal arbitrária e apartada da atenção e do cuidado em saúde, esta cisão sustenta dicotomias confusas e alija um desconhecido e amplo contingente social das possibilidades de vivenciar ativamente, e às claras, a relação subjetividade-drogas. Ao sujeito-usuário são negados e silenciados saberes, fazeres e todas as possibilidades de criação de processos subjetivos não reconhecidos pelos entendimentos conformadores do nosso olhar habitual (ou poderíamos dizer "viciado”?) sobre as drogas.

\section{Transição e alternatividade de paradigmas sobre drogas: proibicionismo e atenção psicossocial a usuários}

$\mathrm{Na}$ esteira das transformações ocorridas principalmente nos países ocidentais e a partir da década de 1980, o modelo de regulação e circulação das substâncias psicoativas no Brasil reúne alguns elementos vanguardistas, mas parece manter e ainda recrudescer em certas conquistas de direitos. Esta dubiedade da atual Política Nacional sobre Drogas está presente em distintos e variados elementos. Entre eles, por exemplo, pode ser citada a convivência, de um lado, de diretrizes orientadas pela Atenção Psicossocial, cuja noção de implicação subjetiva sugere protagonismo e empoderamento do sujeito e, portanto, os processos de conquista e desenvolvimento da autonomia e reposicionamento subjetivo na relação com a substância devem figurar como objetivos de qualquer projeto terapêutico de intervenção ou de programa de prevenção; e, por outro lado, também são identificadas ações e propostas no campo da repressão, endurecimento na aplicação das leis penais e no investimento e custeio de vagas para tratamento de usuários de drogas em instituições totais $^{2}$ do setor civil não governamental, em geral as intituladas Comunidades Terapêuticas. Este cenário nos impõe a discussão e a problematização de seus desdobramentos, pois a afinidade entre os princípios e diretrizes da Atenção Psicossocial e o funcionamento dessas instituições, fundamentalmente ainda asilares, soa, no mínimo, contraditório. 
As noções mais elementares da atenção psicossocial, o empoderamento e a implicação subjetivos (Costa-Rosa, 2013) exigem desdobramentos demasiadamente caros à técnica e aos dispositivos de atenção. Fundamentalmente, deslocam os objetivos terapêuticos da suplantação sintomatológica para o reposicionamento subjetivo diante de seu quadro clínico. A produção de subjetividade autonomizada deve convocar o sujeito ao questionamento e à responsabilização frente ao próprio devir. Tais esforços se chocam com as tratativas focadas na obstrução de liberdades individuais e cerceamento de direitos, presentes nas instituições totais. A atenção aos usuários de drogas, no modelo ambulatorial prestada pelos Centros de Atenção Psicossocial para Álcool e outras Drogas, precisará, também, colocar em prática este protagonismo subjetivo, através do ordenamento de sua funcionalidade tanto técnica quanto de gestão. Um modelo de atenção que coloque este protagonismo no centro das práticas de cuidado necessariamente não pode prescindir do respeito integral a direitos subjetivos básicos; incluindo os de ir e vir, credo, coparticipação nos processos decisórios e nas propostas de intervenção e tratamento. Tal modelo não é certamente o que a absoluta maioria das instituições totais tem apresentado e a apresentar.

Mas, caberia questionarmos: o quê, em termos e desdobramentos práticos, significa a expressão "reposicionamento subjetivo", e qual sua relação com a noção de implicação e empoderamento? Para além da retórica das palavras de efeito, faz-se necessário o esboço dos delineamentos técnicos e das práticas viabilizadoras de tal reposicionamento. Somos pelo entendimento de que as práticas de cuidado sustentadas pelo modelo de atenção psicossocial impõem total reconfiguração sobre o quê entendemos, até o momento, como sendo efetivamente empoderador e promotor de autonomia. Apenas para começo de reflexão, basta reconhecer que a produção de discursos sobre as drogas é, até aqui, de autoria de outrem, nunca pronunciada pela palavra do usuário, especialmente os de droga ilícita. Assim, tal reposicionamento invocaria, antes, necessariamente e no mínimo, os saberes e dizeres sobre as drogas produzidos pelos próprios sujeitos da vivência subjetiva com as drogas.

Um modelo de atenção em saúde a usuários de drogas, nesta perspectiva, necessita, portanto, abandonar a preocupação com a presença e oferta de substâncias para, então, voltar-se ao manejo da condição subjetiva perante a miríade de distintos tipos de drogas e possibilidades de uso. Urge, enfim, preparar o sujeito para produzir a si mesmo com melhor condição de saúde, no tocante à presença do consumo de substâncias psicoativas em nossa sociedade. De antemão, o isolamento social institucionalizado e as práticas de intervenção que não prescindem da condição de monitoramento integral e vigilância baseada na heteronomia não podem se credenciar ao desenvolvimento e formação da implicação subjetiva, nem tampouco da autonomia. A clínica psicossocial para usuários de álcool e outras drogas deve estar posicionada de modo a possibilitar condições de produção de subjetividade no contexto próprio da existência subjetiva. Este contexto inclui o real, o social e o simbólico, na medida em que representa o resultado das condições concretas e materiais, das relações sociais e intersubjetivas, e das representações culturais nas quais o sujeito se insere. Práticas sustentadas pela lógica do isolamento e no cerceamento das vivências de liberdade individual e exercício de autonomia parecem não comungar com tais elementos e princípios.

Desta maneira, os desdobramentos para a atenção aos usuários de drogas são de ordem homérica. O deslocamento do foco de atenção inicialmente recaído sobre a substância em si, ao transladar-se para os processos subjetivos inerentes à conformação dos comportamentos de abuso e adição, invoca exigências à técnica e à ética de cuidados; a começar 
pela admissão a priori da possibilidade de manutenção do uso, a qual provém do anterior e magno direito do livre dispor. Tal admissão implica que, entre as práticas de intervenção, se possa construir, também, conhecimentos minimizadores de danos inerentes ao uso. Os elementos basais mais estruturalmente sustentadores das práticas em Redução de Danos se encontram, portanto, nos mesmos fundamentos legitimadores da condição moderna subjetiva. A liberdade individual está no centro desses fundamentos, e toda estrutura burocrática estatal que tenha sido criada em torno da noção de cidadania deve estar a serviço de garantir a plena vivência dessa existência livre. Às práticas de saúde, cabe o cuidado, "tão somente".

Os desdobramentos à técnica partem desse sedimento legal e, incontinenti, reconhecem a centralidade do sujeito na construção do projeto terapêutico singular. O começo de um projeto de construção de autonomia, assentado no empoderamento subjetivo, deve reconhecer no sujeito a potência para desenvolvimento da convivência entre liberdade, prazer, gozo e autogoverno. O projeto de uma Psicologia indutora dessas condições deve partir do crédito no potencial de um "devir" autonomizado, e seu objetivo final não pode ser outro que não a emancipação dos sujeitos.

\section{Qual "pós-proibicionismo” é possível?}

Em oposição ao paradigma proibicionista sobre as drogas, naquilo que entendemos ser realmente de transposição paradigmática, aludimos a uma condição de relação da sociedade com as drogas, quiçá outrora presente, e que no contemporâneo teria se perdido. Aludimos à condição de aventar por quais meios nossa sociedade poderia reconhecer não apenas a inevitabilidade da presença de drogas em circulação, mas também que o uso delas poderia ser de valor psíquico experimental e fornecedor de contrapesos e possibilidades de contornos intersubjetivos escapistas à normalidade gestora de sofrimento. Portanto, com potencial regulador e homeostático na busca de condições de saúde e vivência social equilibrada. Um uso que pudesse constituir, também, em usufruto; empréstimo de uma morada transitória. Não apenas a recomunhão com a valorização da função do gozo, mas também a reconquista dos saberes que visem a uma regulação com as drogas poderiam e deveriam ser almejadas. Um paradigma que se pretenda suplantador do nosso atual estado de inabilidade para com as drogas deve partir da necessidade básica de compreendê-las sem a opacidade dos discursos enviesados. As diferentes "verdades" que foram construídas em torno das drogas ao longo do século passado atestam a fecundidade que este desconhecimento tem em produzir agravos. O ponto de mutação poderia ser um entendimento que nos levaria à busca por certa "educação para o consumo de drogas", e não "apenas" ao desenvolvimento de técnicas e estratégias redutoras de danos inevitáveis. Estamos falando francamente de se admitir e vivenciar possibilidades de uso de drogas em associação e convivência, relativamente pacífica, com condições gerais de saúde (incluídas as dimensões emocionais, psíquicas, fisiológicas e sociais).

Óbvia e reiteradamente repetimos que não se trata, em absoluto, de não reconhecer todo o potencial aditivo das substâncias psicoativas, nem tão pouco ignorar a parcela de usuários que, de fato e clinicamente, se despersonalizam em função da ingovernabilidade da compulsão em certos padrões de uso, para certos tipos de drogas. Para nos lembrarmos ad eternum dessas condições, há um arsenal de meios de comunicação alarmistas e ávidos 
por fomentar o consumo de informações dramatizadas e produtoras de percepção catastrófica. Pensar em qualquer nível de "educação para o consumo de drogas" nunca deverá se confundir com o desconhecimento de seu potencial de ofensividade, nem tão pouco sugerir derrotismo conformista com seus possíveis danos. Ao contrário, este novo paradigma implicará em um esclarecido debate acerca das drogas, no melhor sentido a que estamos fazendo referência ao "esclarecimento". Qualquer que seja o ponto de vista adotado, o fato é que a intangibilidade do objeto-drogas, que nos é tão caro e fugidio, é uma produção social certamente relacionada com este estado de circulação de conhecimentos velados, dos interditos, das lacunas e dos não-saberes sobre as drogas; essências fundamentais na configuração do paradigma proibicionista. Uma transposição deste atual estado de coisas não se fará apenas com aprovação de aparato legal, ainda mais se recheado de contradições e incapaz de se concretizar nas instituições que operam as relações da sociedade com as drogas.

A quase infinita quantidade de questões e interesses difusos, em contradição e desacordo com razões verdadeiramente alinhadas aos debates que teriam por objetivo a busca por condições de saúde, fez da "questão-drogas" um obscuro e incompreendido fenômeno psíquico e social, produtor e reprodutor de divergentes discursos e entendimentos sobre o lugar das substâncias psicoativas na sociedade. Este estado de saber obscurecido atinge a condição de um não-saber, que é o que fica disponível ao usuário como plataforma de sua relação com as drogas. Em oposição, uma dada condição esclarecida na relação sujeito-drogas suporia outro patamar na própria produção dos saberes em saúde. Entre tantos exemplos sobre como a "gestão dos conhecimentos" sobre as drogas pode ser enviesada, bastaria reconhecer minimamente que qualquer sociedade que se proponha a discutir e decidir os rumos de suas políticas sobre drogas deve necessariamente incluir neste debate as questões sobre consumo de medicamentos psicotrópicos. No meio de muitas outras urgências, esta é uma das lacunas crassas de nossa sociedade e nossa política sobre drogas. Os medicamentos psicotrópicos no Brasil são largamente consumidos, sem que verdadeiramente se tenha um aprofundado debate e um conjunto de informações e conhecimentos suficientes sobre, por exemplo, potencial de adição e arranjos possíveis das funções psicoativas na relação com a constituição intersubjetiva. Em verdade e a rigor, o que se observa é uma crescente medicalização da sociedade como um todo, sustentada por discursos de curabilidade de um leque cada vez maior de características e padrões de comportamento tipologizáveis, produzidos, ao melhor estilo do modo de produção capitalista, pelos monumentais interesses das indústrias farmacêutica e química pelo mundo. No Brasil, em particular, da infância "ritalinizada" à vida adulta "diazepinizada", pouco ou nada se tem dito sobre os impactos à saúde desta população usuária de drogas.

Outra prioridade gravemente negligenciada pela atual política e modelo de atenção refere-se ao preciso dimensionamento da extensão dos impactos causados pelo consumo massivo de álcool. O álcool é substância psicoativa consumida em escala ampliada, amparada por todo um sistema oficial de gerenciamento desta droga, que envolve desde criativa e premiada publicidade a sistema de arrecadação de tributos e outras relações menos briosas com a indústria. Seu consumo é alastrado para todas as classes sociais e também inexiste circulação de precisos e apurados conhecimentos acerca das melhores práticas e hábitos de consumo disponíveis. Somemos a este cenário ideologizado e enviesado da produção de saberes sobre as drogas, os apontamentos, já trazidos neste breve ensaio, tais como: o funcionamento das instituições operadoras do Direito, as práticas de encarcera- 
mento penal e suas características, os desdobramentos em termos de violência e corrupção dessas mesmas instituições. O conjunto destes condicionantes nos convoca a sustentar que o almejado ponto de mutação na relação dos sujeitos e das sociedades com as drogas não se encontra apenas no desenvolvimento de instrumental técnico minimizador de danos e nos mecanismos lenitivos à condição irreversivelmente danosa dos efeitos do consumo de drogas pelas populações. Trata-se, em nosso entendimento, de questão profundamente filosófica e psicológica. Tal deslocamento subjetivo, da posição de automatizado para a de "usufruturário" das funções psicoativas das drogas, impõe a noção proposta de "esclarecimento". Ainda que todo consumo de drogas, como premissa, esteja imediatamente relacionado à noção de risco, melhores condições de desenvolvimento humano e subjetivo são o que se poderia chamar de "fator de proteção". Por isso a ênfase no reposicionamento do sujeito e não na acessibilidade às drogas.

Esta condição esclarecida suporia, por sua vez, a formação um conjunto de saberes sobre as drogas até aqui negado aos usuários e à sociedade como um todo. Compreender melhor o lugar das drogas entre nós implica na consciência de uma quantidade significativa de condicionantes. Da formação de mercado internacional à geopolítica, dos conhecimentos sobre cadeia de produção, distribuição e sustentabilidade, passando pelos saberes sobre a Justiça, Direito e as liberdades individuais. Conhecimentos sobre reais efeitos, potencial aditivo e psicoativo, dosagem, práticas de uso seguro e especificações de qualidade. Elementos que, combinados, poderão fornecer aos sujeitos melhor condição de desenvolver mais apurado e sensível "saber-usar" na construção de uma dada relação com as drogas. Contrariamente ao que o paradigma proibicionista buscou determinar, as drogas "precisam ser conhecidas"! O acesso a este saber poderá significar melhores condições de formação de uma razão desentorpecida; o que anunciaria, mais realisticamente e de fato, outro paradigma.

Desta forma, a problematização que este artigo intenta realizar aponta para algo que poderia ser intitulado como "educação para as drogas". O alinhamento com as diretrizes e princípios da atenção psicossocial para a Saúde Mental se darão na confluência entre a garantia das liberdades individuais e o empoderamento subjetivo, mediante os princípios técnicos e o posicionamento ético imposto por tal modelo. Por natureza e definição, este modelo de atenção não pode se edificar sobre entendimentos calcados no proibicionismo, pois estes são, essencialmente, moldados pela negação do potencial emancipatório que os sujeitos podem manter e/ou desenvolver na e pela relação com as drogas. O paradigma proibicionista, pela premissa da defesa da interdição do Estado no "devir" dos sujeitos, é conceitualmente contrário à atenção psicossocial, pois todo projeto ou ação interventiva nele fundamentado anula, na raiz, o potencial da razão autonomizada. O gerenciamento da circulação das drogas, pela perspectiva do proibicionismo, veta e cancela o livre dispor autônomo, relegando aos sujeitos o ajustar-se ou o transgredir das forças de biopoder. Negar aos sujeitos o acesso à realidade e vivência das drogas, mesmo que travestido de real intenção protetiva, se contrapõe às exigências da formação subjetiva emancipada e total; cerceia e submete os sujeitos ao jugo da força e transfere ao Estado o arbítrio sobre a vida.

O uso desse enorme conjunto de produtos, plantas e moléculas tem diversas motivações, e parte delas são de indiscutível importância para a humanidade: ajudam no enfrentamento de doenças e infecções, aliviam a dor, apaziguam a ansiedade, melhoram o desempenho, despertam prazer, excitam, inspiram 
reflexões, facilitam relações sociais e, o que talvez seja uma combinação de cada uma dessas coisas, suspendem a forma ordinária de perceber o mundo. Por essas e muitas outras razões, os seres humanos as procuraram em toda a história e continuarão a fazê-lo. Como outras experiências e práticas liminares, essa alteração é arriscada e, por isso mesmo, o consumo de substâncias psicoativas foi sempre cercado de controles e interdições sociais. O exagero da premissa proibicionista é fazer do Estado, cujo motivo primordial de existência é a garantia de liberdades e direitos individuais, o promotor dessas interdições por meio da criminalização que impeça a adultos dispor de seus corpos (e ainda supor, como será discutido a seguir, que eles, com isso, deixarão de fazê-lo). Isso não é o mesmo que advogar por um cenário libertário radical, potencialmente inconsequente, em que ao indivíduo é dada uma autossuficiência abstrata. Sabe-se que o Estado se constrói em permanente arena de conflitos de interesses e valores, alguns antagônicos, mas deve haver limites para sua atuação. As práticas corporais e a ingestão de substâncias devem ser um desses marcos de autonomia, e as interdições tutelares só se justificariam em casos individuais com cuidadoso processo médico-judiciário. E, se esse é o caso do consumo de algumas substâncias hoje proscritas, então o Estado teria, por decorrência, que estender a interdição para um campo geral das drogas, dos alimentos e até de outras práticas tidas como "perigosas". O braço mais poderoso e, portanto, perigoso do Estado é a punição e, por isso, seu uso deve ser sempre considerado um recurso excepcional. (Fiore, 2012, p. 13)

\section{Considerações finais}

Encontramo-nos, pois, em momento assemelhado a uma encruzilhada técnica, conceitual e política. As discussões muito se referem à transição de paradigmas, mas as práticas e mesmo as políticas públicas patinam nos arraigados entendimentos e na cultura de consumo massivo e irreflexivo. Os patamares e padrões de consumo seguem elevados e seguirão impactando gravemente usuários e não usuários a permanecerem com os mesmos valores e os saberes velados, os quais não possibilitam a construção de entendimentos úteis na relação usuário-drogas. Uma condição que signifique e inaugure o modelo e paradigma "pós-proibicionista" não poderá prescindir de uma revolução no estado das coisas, e não apenas ensaiar retóricas reformistas sobre as práticas de atenção. Dizemos retóricas reformistas porque, fundamentalmente, os usuários abusivos de drogas permanecem nas mesmas condições de ilegalidade e clandestinidade, desassistidos e relegados a serviços de atenção principalmente extra-oficiais; os usuários ocasionais seguem desinformados e desorientados sobre boas práticas de manejo e uso das drogas; crianças e adolescentes seguem sem ter acesso a um debate consubstanciado e pautado pelas condições de saúde; o mercado de drogas lícitas segue se beneficiando da complacência do Estado e suas instituições, pois a ele recolhe vultosos tributos e dele recebe a permissividade necessária. Com direito a uso de publicidade e descontrole e desregulamentação do acesso. Já o mercado de drogas ilícitas se beneficia da desregulamentação e até mesmo da proibição, pois são desenvolvidos mecanismos de adaptação às vãs tentativas de esgotamento da oferta e às sanções, ao mesmo tempo em que incorrem na corrupção das instituições e dos operadores do Direito e na cronificação das condições calamitosas dos presídios. 
A arbitrariedade com que os conhecimentos sobre drogas são produzidos não significa outra coisa senão o reverso do esclarecimento. $\mathrm{O}$ que sabemos, na prática, não passa muito de formulações opacas e patrocinadas por interesses diversos construídos ao longo do século passado. Esses saberes ignoraram o fato de as drogas somente terem sentido cognoscível quando são entendidas como sendo resultado das relações que com elas os usuários estabelecem, e não possuindo uma verdade definível de antemão e inquestionável. A “verdade" sobre as drogas, justamente por seu caráter transitório e fugidio, sujeita a significantes variáveis tanto quanto são as possibilidades e processos de subjetivação, desaconselha, portanto, a proposição de saberes doutrinantes e terminantes. A Atenção Psicossocial propõe reformulações de ordem estrutural aos aportes teórico-técnicos, pois convoca o sujeito-usuário ao protagonismo e à coautoria sobre suas próprias tratativas. Neste sentido, além de abordagens tradicionais calcadas nas ciências do comportamento, cujas matrizes teóricas são de vertentes funcionalistas, e dos referenciais da psicanálise, atentos ao funcionamento psíquico e à psicodinâmica da relação sujeito-drogas, o modelo de atenção psicossocial convoca também abordagens psicossociais, que se aproximam dos objetivos de reconhecimento e consciência das relações intersubjetivas e do lugar do sujeito na construção dessas mesmas relações. Este modelo de atenção requer um ativismo difícil de ser conciliado com tratativas alicerçadas em pressupostos que atestem a ingovernabilidade da volição e do desejo do usuário. Tal deslocamento, desde evitar a substância inadministrável à construção de condições de esclarecimento e emancipação sobre a mesma, requererá, de fato, a tal suplantação paradigmática. A transição do proibicionismo para outro estado de entendimento não é somente condição para a atenção psicossocial, mas se confunde com a própria.

Não apenas estamos falando da imprescindível reforma dos fundamentos legais e institucionais, visando à plena garantia das liberdades individuais e dos direitos humanos; não apenas a reforma dos dispositivos de atenção e cuidado, visando à efetivação de um modelo de atenção integral que protagonize a subjetividade; não apenas uma revolução de ordem cultural, que redefina o lugar das drogas numa dada sociedade; o paradigma e a condição pós-proibicionistas se darão se e quando o conjunto dessas transformações se articularem integralmente; quando a atenção psicossocial se consolidar como práticas e lógica de cuidado disseminada e incorporada pelos profissionais; quando os dispositivos estiverem aparelhados e adequados para promover cidadania e protagonismo social; quando a cultura circulante reconhecer o lugar das drogas em meio as tensões e fraturas sociais, e com seus usuários souber relacionar-se aberta e francamente; quando, enfim, a página do proibicionismo, em nível internacional e doméstico, houver sido superada de fato e substancialmente. Esta condição, na prática e a rigor, é ainda desconhecida, mesmo que em alguns países certos e consistentes passos adiante já tenham sido dados. A nós significaria uma relação com as drogas a partir de um patamar de saberes esclarecidos, que as reconheça e as integre equilibradamente às trocas intersubjetivas e expressões da vida em sociedade. Não há, queiramos ou não, que falarmos em sociedade livre do uso de drogas. Uma premissa como tal se configura em ingênua e falaciosa intenção de gerenciamento dos corpos e saberes sobre os mesmos. Além de falacioso, na atualidade, esta proposição tem causado vultosos impactos sobre a saúde dos usuários, conflitos sociais, violência e iníquas práticas e intervenções do Estado sobre parcelas específicas da população. Outro estado de entendimento e práticas urge e a nós, profissionais de saúde e pesquisadores, recaem inescusáveis responsabilidades. 


\section{Notas}

1 Por "biopolítica" ou controle biopolítico do Estado deve ser entendido os diferentes modos de gestão de corpos e subjetividades, por meio de práticas disciplinares, com fins de produzir padronização de comportamentos e de distinção entre normalidade e anormalidade. Conceito inicialmente proposto por Michel Foucault (2008), nos auxilia a compreender as tecnologias de gestão e disciplinarização de corpos, subjetividades e comportamentos na virada do século XIX para o XX.

2 Por instituições totais deve-se entender aquelas cuja inserção dos indivíduos se dá na totalidade de suas ações e práticas cotidianas, em regime de internato e moradia diuturna, sob funcionamento institucional regulador e determinante das vivências intersubjetivas.

\section{Referências}

Alarcon, S. (2008). O diagrama das drogas como dispositivos de poder na sociedade brasileira contemporânea. Tese de Doutorado, Programa de Pós-graduação em Saúde Pública, Escola Nacional de Saúde Pública Sérgio Arouca/Fundação Oswaldo Cruz, Rio de Janeiro, RJ.

Costa-Rosa, A. (2013). Atenção Psicossocial Além da Reforma Psiquiátrica: contribuições da Clínica Crítica aos processos de subjetivação na Saúde Coletiva. São Paulo: Editora Unesp.

Escohotado, A. (2005). História General de las Drogas: fenomenologia de las drogas. Espanha: Espasa.

Fiore, M. (2012). O lugar do Estado na questão das drogas: o paradigma proibicionista e as alternativas. Revista Novos Estudos - Cebrap, 92, 9-21.

Foucault, M. (2008) The Birth of Biopolitics: Lectures at the Collège de France, 1978-1979. Basingstoke: Palgrave Macmillan.

Fuente, A. V. (1992). Modelos Interpretativos de la Problematica de las Drogas. Revista Española de Drogodepencia, 4(17), $221-232$.

Karam, M. L. (2009). Proibições, riscos, danos e enganos: as drogas tornadas ilícitas (Vol. 3). Rio de Janeiro: Lumine Juris.

Lei Federal n. 11.343, de 23 de agosto de 2006. (2006). Institui o Sistema Nacional de Políticas sobre Drogas e dá outras providências. Brasília, DF: Presidência da República.

Macrae, E. J. B. N. (1994). A abordagem etnográfica do uso de drogas. In F. Mesquita \& F. I. Bastos (Eds.), Drogas e Aids estratégias de redução de danos. (pp. 99-1 14). São Paulo: Hucitec.

Ministério dla Saúde.(2003a). A Política do Ministério da Saúde para atenção integral a usuários de álcool e outras drogas. Brasília, DF: Autor.

Ministério da Saúde.(2003b). Política Nacional Antidrogas. D.O.U. N. 165, 27/08/2002. Brasília: DF: Autor.

Ministério da Saúde. (2004). Saúde Mental no SUS: Os Centros de Atenção Psicossocial. Secretaria de Atenção à Saúde. Brasília, DF: Autor.

Rodrigues, L. B. (2006). Controle Penal sobre as Drogas: o impacto do Proibicionismo sobre o sistema penal e a sociedade. Tese de Doutorado, Programa de Pós-graduação em Direito, Faculdade de Direito da Universidade de São Paulo, São Paulo. 
Rose, N. (1999). Powers of Freedom: Reframing Political Thought. Cambridge: Cambridge University Press.

Thompson, J. (2012). Ideologia e Cultura Moderna: teoria social crítica na era dos meios de comunicação de massa. Petrópolis, RJ: Vozes.

\section{FÁBIO JOSÉ ORSINI LOPES}

https://orcid.org/0000-0001-6827-820X

Professor Adjunto do Departamento de Psicologia da Universidade Estadual de Maringá - UEM/PR.

Endereço Institucional: Avenida Colombo, 5.790, Jardim Universitário, CEP 87020-900, Maringá-PR; Universidade Estadual de Maringá, Departamento de Psicologia, bloco 118.

E-mail: fabio.jose.lopes@hotmail.com

$\begin{array}{cl} & \text { Submissão: 20/11/2017 } \\ \text { Histórico } & \begin{array}{l}\text { Revisão: 02/10/2018 } \\ \text { Aceite: } 20 / 11 / 2018\end{array} \\ \text { Contribuição dos autores } & \text { Não se aplica } \\ \text { Financiamento } & \text { Não se aplica } \\ & \text { Não se aplica }\end{array}$

